\title{
https://doi.org/10.46813/2021-133-104 \\ ESTIMATION OF GROSS-STRUCTURE PARAMETERS OF GIANT DIPOLE RESONANCE: 1. A METHOD
}

\section{V.L. Uvarov, A.A. Zakharchenko \\ National Science Center “Kharkov Institute of Physics and Technology”, Kharkiv, Ukraine E-mail: uvarov@kipt.kharkov.ua}

\begin{abstract}
Available data on photonuclear cross-sections, both measured experimentally and obtained on the basis of theoretical models, are characterized sometimes by a considerable spread. In work, a simple method for the estimation of width (FWHM) and maximum $\left(\sigma_{\max }\right)$ of excitation function of a reaction with dominant giant dipole resonance, is given. An analytical model is developed for the description of isotope production in an X-ray beam. It is shown, that the established yield of the reaction in a thin target, overlapping completely the beam with known end-point photon energy makes it possible to estimate the $\sigma_{\max }$ and FWHM values. The possibilities of new approach are demonstrated by a numerical experiment on the reference reactions.
\end{abstract}

PACS: 07.05.Tr, 41.50.+h; 41.75.Fr; 78.70En

\section{INTRODUCTION}

Precise determination of excitation function of a photonuclear reaction is commonly associated with the considerable difficulties. The main sources of the uncertainty are the nonmonochromaticity and nonuniformity of a photon beam. In its turn at theoretical description of giant dipole resonance (GDR), it is necessary to consider the symmetry of a nucleus, the isospin and configurational splitting, etc. That is why, the available data on the cross-sections, both obtained in the different experiments and calculated on the basis of different theoretical models, are characterized by a significant scatter (see e.g. [1, 2]). At the same time, the development of methods of the isotope production with the use of electron accelerator, taking place for the last two decades, poses the necessity of more accurate data on the reaction parameters for the estimation of capacity and isotopic purity of a product obtained.

For a problem like that, there is no need in the detailed description of excitation function. It is quite enough to just know the key parameters of the GDR gross-structure. Those parameters, followed in ascending order of uncertainty of the available data, are:

- the reaction threshold, $E_{\mathrm{th}}$;

- the photon energy corresponding to maximum of excitation function, $E_{\max }$;

- FWHM of the excitation function, $\Gamma$;

- the maximum of the cross-section, $\sigma_{\text {max }}$.

In the current work, a novel method for estimating the $\Gamma$ and $\sigma_{\max }$ values is proposed. The method is based on a developed analytical model for calculation of reaction yield in a bremsstrahlung radiation field (S-model), and also on a limited number of experimental data. The accuracy of the technique is checked by its application to the reactions ${ }^{58} \mathrm{Ni}(\gamma, \mathrm{n}){ }^{57} \mathrm{Ni}$ and ${ }^{100} \mathrm{Mo}(\gamma, \mathrm{n}){ }^{99} \mathrm{Mo}$. Their gross-structure parameters are quite different (Table 1). At the same time, the theoretical description of the cross-section of those reactions [3] is generally in good agreement with the experimental data $[4,5]$. The asterix at the $\Gamma$ value for the ${ }^{58} \mathrm{Ni}(\gamma, \mathrm{n}){ }^{57} \mathrm{Ni}$ reaction denotes, that the part of the excitation function having a local maximum near the reaction threshold in the theo- retical description [3] has been smoothed IAW the experimental data [4].

Table 1

Characteristics of excitation function of reference reaction

\begin{tabular}{|c|c|c|c|c|}
\hline Reaction & $\begin{array}{c}E_{\text {th }}, \\
\mathrm{MeV}\end{array}$ & $\begin{array}{c}E_{\max }, \\
\mathrm{MeV}\end{array}$ & $\begin{array}{c}\Gamma, \\
\mathrm{MeV}\end{array}$ & $\begin{array}{c}\sigma_{\max }, \\
\mathrm{mb}\end{array}$ \\
\hline${ }^{58} \mathrm{Ni}(\gamma, \mathrm{n})^{57} \mathrm{Ni}$ & 12.21 & 18.7 & $7.1 *$ & 26.0 \\
\hline${ }^{100} \mathrm{Mo}(\gamma, \mathrm{n}){ }^{99} \mathrm{Mo}$ & 8.29 & 14.2 & 3.9 & 149.0 \\
\hline
\end{tabular}

\section{ANALYTICAL MODEL \\ 1.1. KEY CHARACTERISTICS OF PROCESS}

The yield of a photonuclear reaction in a target by volume $V$ irradiated with an X-ray beam, reduced to the one electron of a primary beam with energy $E_{\mathrm{e}}$ can be determined from the equation [6].

$$
y\left(E_{e}\right)=\frac{N_{A}}{\bar{A}} v \rho \int_{V} d V \int_{E_{t h}}^{E_{e}} \varphi_{\gamma}(E, \vec{r}) \sigma(E) d E,
$$

where $N_{A}$ is the Avogadro number, $\bar{A}$ is the average atomic mass of the target material, $\rho$ is its density, $v$ is the relative concentration of the isotope-target nuclei, $\varphi(E, \vec{r})$ is the differential fluence of X-ray photons with energy $E$ in the point $\vec{r}, \sigma(E)$ is the reaction cross-section.

The reaction yield can be measured most accurately in a case of a thin target (by mass thickness $\Delta<<\mu^{-1}\left(E_{\mathrm{th}}\right)$, where $\mu$ is the photon attenuation coefficient in the target material), overlapping in full the X-ray beam and normal to its axis. Such a target is called a photonuclear converter $(\mathrm{PNC})-[7]$. Its activity, $A_{P N C}$, induced by electron beam with average current $I$ at the end of the irradiation period $t$, can be determined by the equation

$$
A_{P N C}=Y_{0}\left(E_{e}\right) \frac{I}{e} \Delta[1-\exp (-\lambda t)]
$$

where $\lambda$ is the decay constant of the isotope-product,

$$
Y_{0}\left(E_{e}\right)=\frac{N_{A}}{\bar{A}} v \int_{E_{t h}}^{E_{e}} n_{\gamma}(E) \sigma(E) d E,
$$

$n_{\gamma}(E)$ is the spectral density of bremsstrahlung photons normalized to the one beam electron. 
$Y_{0}$ is called the coefficient of photonuclear conversion (CPC) [6]. Its value does not depend on the size and position both the electron beam and the X-ray flux as well as on the PNC position relative to the radiation. So, the $Y_{0}$ quantity includes the minimum of parameters affecting the uncertainty of its measurement. Thus, $Y_{0}$ describes the photonuclear isotope yield most accurately, and it is convenient for estimating the data on a cross-section obtained from the different sources.

In a physical meaning $Y_{0}$ corresponds to the yield of the isotope-product in PNC by single mass thickness. That coefficient enters as a factor into the expressions for the gross and specific activity of an arbitrary thick target. Thus, it is a critical parameter of the capacity of a photonuclear technology [6].

\subsection{SPECTRUM OF $\mathrm{X}$-rays}

In [8], a simple expression was proposed for spectral distribution of bremsstrahlung photons escaping a thick converter commonly used in photonuclear technologies to increase the photon yield

$$
n_{\gamma}\left(E, E_{e}\right)=2 \eta\left(E_{e}\right)\left(E^{-1}-E_{e}^{-1}\right),
$$

where $\eta\left(E_{e}\right)$ is the coefficient of energy conversion of electron into X-ray radiation. It can be measured experimentally with the use of a thick-wall ionization chamber or calculated by a simulation technique.

From formula (4), one can obtain the expression for the number of above-threshold photons generated by one electron

$$
N_{\gamma}\left(E_{t h}, E_{e}\right)=2 \eta\left(E_{e}\right)\left[E_{t h} \cdot E_{e}^{-1}-\ln \left(E_{t h} \cdot E_{e}^{-1}\right)-1\right] .
$$

As an example, the spectra of X-rays with energy higher than $8.29 \mathrm{MeV}$ (the threshold of the ${ }^{100} \mathrm{Mo}(\gamma, \mathrm{n}){ }^{99} \mathrm{Mo}$ reaction) at an electron energy of $40 \ldots 95 \mathrm{MeV}$ are plotted in Fig. 1. That range corresponds to the beam parameters of a LU-40 accelerator operating in NSC KIPT and providing experimental study of photonuclear processes [9]. In calculations, a converter from tantalum by $4 \mathrm{~mm}$ in thickness was considered. It was shown earlier, that such size is close to optimal to provide the maximum of conversion of electron beam into bremsstrahlung radiation [8]. In Table 2, the $N_{\gamma}$ value is listed. Both calculated with the formula (5) and obtained by simulations using a transport code GEANT4 [10]. The spectral region with photon energy $E<E_{\text {th }}$ was out of consideration, as such radiation contributes only to the heating of a target.

Table 2

Normalized yield of above-threshold photons

\begin{tabular}{|c|c|c|c|}
\hline$E_{e}$, & $\eta$ & \multicolumn{2}{|c|}{$N_{\gamma}$, phot./e } \\
\cline { 3 - 4 } $\mathrm{MeV}$ & rel. un. & GEANT4 & Formula (5) \\
\hline 40 & 0.42 & 0.60 & 0.64 \\
\hline 60 & 0.44 & 0.92 & 0.99 \\
\hline 80 & 0.45 & 1.19 & 1.24 \\
\hline 95 & 0.46 & 1.37 & 1.39 \\
\hline
\end{tabular}

It is seen, that the proposed analytical expression describes the yield of high-energy photons from the thick converter with overestimation, that is not higher than $8 \%$.
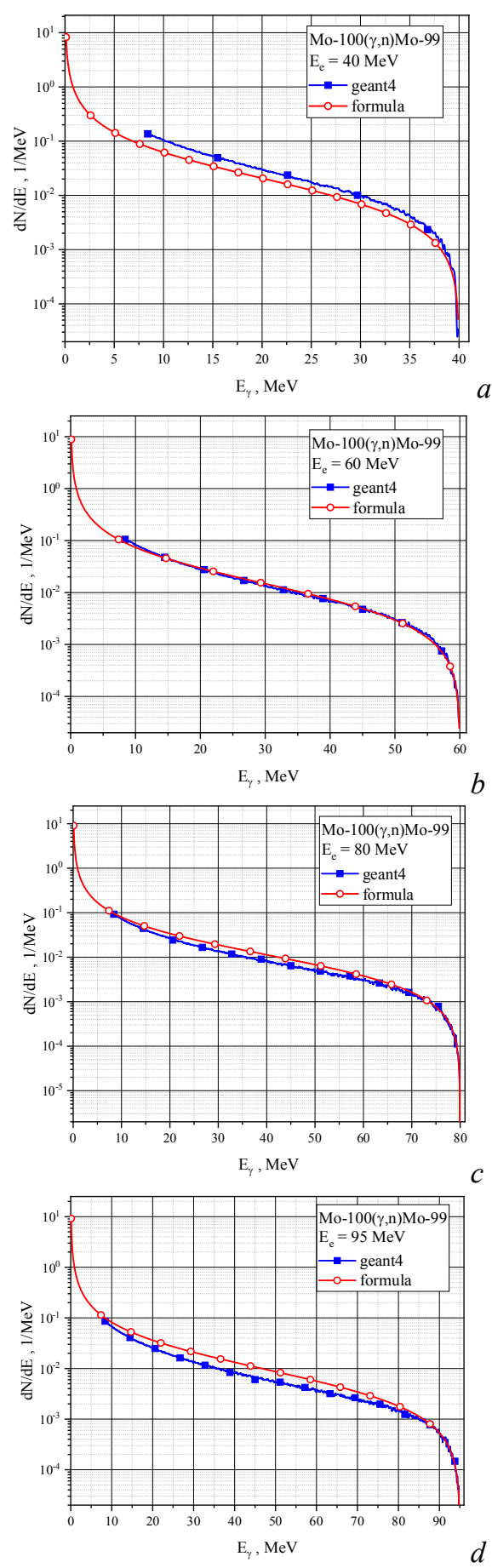

Fig. 1. Spectra of $X$-rays:

$E_{e}=40 \mathrm{MeV}(a) ; E_{e}=60 \mathrm{MeV}(b)$;

$E_{e}=80 \mathrm{MeV}(c) ; E_{e}=95 \mathrm{MeV}(d)$

\subsection{EXCITATION FUNCTION OF GDR}

The generally adopted approximation of GDR grossstructure is its representation in the form of Lorentzian (see e.g. [1])

$$
\sigma(E)=\sigma_{\max } \frac{(E \Gamma)^{2}}{\left(E^{2}-E_{\text {max }}^{2}\right)^{2}+(E \Gamma)^{2}} .
$$

In Fig. 2, the excitation functions of the reference reactions, taken from the TALYS library, and also their Lorentz representations normalized to $\sigma_{\max }$, are shown. 

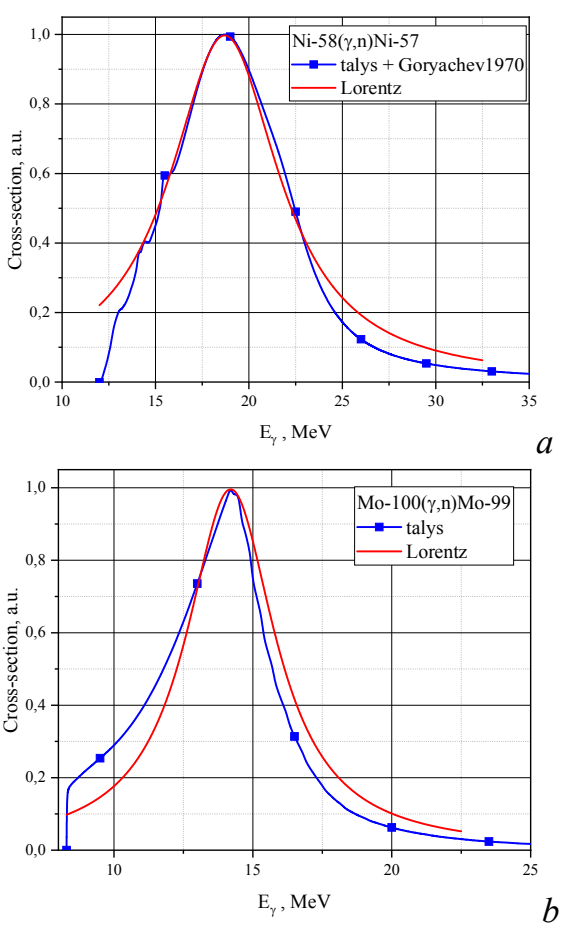

Fig. 2. Normalized excitation functions of reference reactions:

${ }^{58} \mathrm{Ni}(\gamma, n){ }^{57} \mathrm{Ni}(a) ;{ }^{00} \mathrm{Mo}(\gamma, n){ }^{99} \mathrm{Mo}(b)$

\subsection{CONVOLUTION OF X-ray SPECTRUM AND EXCITATION FUNCTION}

The description of spectrum of the high-energy Xrays by the expression (4) and of GDR cross-section by Lorentzian enables to obtain an analytical expression for the CPC

$$
Y_{0}\left(E_{e}\right)=\eta\left(E_{e}\right) \frac{N_{A}}{\bar{A}} v \sigma_{\max } S\left(E_{e}\right),
$$

where

$$
S\left(E_{e}\right)=2 \int_{E_{t h}}^{E_{e}} \frac{(E \Gamma)^{2}}{\left(E^{2}-E_{\max }^{2}\right)+(E \Gamma)^{2}}\left(1-\frac{E}{E_{e}}\right) \frac{d E}{E} .
$$

Thus the S-factor is the convolution of normalized excitation function and bremsstrahlung spectrum. The expression (7) for a reaction's CPC includes S-factor as a dimensionless correction coefficient, that takes into consideration the width of GDR and profile of spectrum of the high-energy photons.

After substitution of variables in the expression (8)

$$
\varepsilon=E / \Gamma ; \varepsilon_{\max }=E_{\max } / \Gamma ; \varepsilon_{\mathrm{e}}=E_{\mathrm{e}} / \Gamma ; \varepsilon_{t h}=E_{\mathrm{th}} / \Gamma
$$

and integration, we have

$$
S\left(\varepsilon_{e}\right)=2\left[\Psi\left(\varepsilon_{e}\right)-\Psi\left(\varepsilon_{t h}\right)\right]
$$

where

$$
\begin{aligned}
& \Psi(\varepsilon)=\left[\left(2 \varepsilon_{e}\right)^{-1}-D^{-1}\right] \operatorname{arctg}(D-2 \varepsilon)-\left[\left(2 \varepsilon_{e}\right)^{-1}+D^{-1}\right] \operatorname{arctg}(2 \varepsilon+D)+(4 \varepsilon D)^{-1} \ln \left(\frac{D \varepsilon+\varepsilon_{\max }^{2}+\varepsilon^{2}}{D \varepsilon-\varepsilon_{\max }^{2}-\varepsilon^{2}}\right) \\
& D=\left(4 \varepsilon_{\max }^{2}-1\right)^{1 / 2}
\end{aligned}
$$

The S-factor of the reference reactions, calculated using the formula (10) and data of Table 1, is presented in Tables 3, 4. At changing of gross-structure parameters, an estimate of S-factor variability demonstrates relatively weak dependence on $E_{\max }$ (from 9 to $5 \% / \mathrm{MeV}$ for the reaction ${ }^{100} \mathrm{Mo}(\gamma, \mathrm{n}){ }^{99} \mathrm{Mo}$ and from 5 to $2 \% / \mathrm{MeV}$ for the reaction ${ }^{58} \mathrm{Ni}(\gamma, \mathrm{n}){ }^{57} \mathrm{Ni}$ in the electron energy range from 40 to $95 \mathrm{MeV}$ ). At the same time, the dependence of $\mathrm{S}$-factor on $\Gamma$ is more strongly expressed.

$$
\text { S-factor of reaction }{ }^{58} \mathrm{Ni}(\gamma, n)^{57} \mathrm{Ni}
$$

Table 3

\begin{tabular}{|c|c|c|c|c|}
\hline \multirow{2}{*}{$\begin{array}{c}E_{\mathrm{e}}, \\
\mathrm{MeV}\end{array}$} & \multicolumn{4}{|c|}{$\Gamma, \mathrm{MeV}$} \\
\cline { 2 - 5 } & 6 & 7 & 8 & 9 \\
\cline { 2 - 5 } & \multicolumn{4}{|c|}{$S$-factor } \\
\hline 40 & 0.413 & 0.462 & 0.505 & 0.545 \\
\hline 60 & 0.551 & 0.619 & 0.681 & 0.738 \\
\hline 80 & 0.622 & 0.701 & 0.773 & 0.840 \\
\hline 95 & 0.657 & 0.740 & 0.818 & 0.889 \\
\hline
\end{tabular}

S-factor of reaction ${ }^{100} \mathrm{Mo}(\gamma, n)^{99} \mathrm{Mo}$

\begin{tabular}{|c|c|c|c|c|}
\hline \multirow{2}{*}{$\begin{array}{c}E_{\mathrm{e}}, \\
\mathrm{MeV}\end{array}$} & \multicolumn{4}{|c|}{$\Gamma, \mathrm{MeV}$} \\
\cline { 2 - 5 } & 3.5 & 4 & 4.5 & 5 \\
\hline 40 & 0.426 & 0.476 & 0.523 & 0.568 \\
\hline 60 & 0.511 & 0.573 & 0.631 & 0.687 \\
\hline 80 & 0.555 & 0.622 & 0.686 & 0.48 \\
\hline 95 & 0.576 & 0.646 & 0.713 & 0.777 \\
\hline
\end{tabular}

\section{ESTIMATION OF GROSS-STRUCTURE PARAMETERS}

\subsection{CALCULATION OF CPC OF REFERENCE REACTIONS}

If the GDR parameters of a reaction are specified, its yield can be calculated by (2) - (10) or by means of MC simulations. As an example, the value of CPC of the reference reactions in natural nickel and molybdenum $\left(v\left({ }^{58} \mathrm{Ni}\right)=0.6827, v\left({ }^{100} \mathrm{Mo}\right)=0.0963\right)$ is listed in Table 5. The results of simulations, as the reference data, were obtained using the GEANT4 and TALYS packages. The analytical calculations were conducted on the basis of Smodel (formula (2)) and findings of Tables 2-4.

Table 5 CPC of reference reactions, $Y_{0}\left(E_{\mathrm{e}}\right) \cdot 10^{5}, \mathrm{~cm}^{2} / \mathrm{g}$

\begin{tabular}{|c|c|c|c|c|}
\hline \multirow{2}{*}{$\begin{array}{c}\mathrm{E}_{\mathrm{e}}, \\
\mathrm{MeV}\end{array}$} & \multicolumn{2}{|c|}{${ }^{58} \mathrm{Ni}(\gamma, \mathrm{n})^{57} \mathrm{Ni}$} & \multicolumn{2}{c|}{${ }^{100} \mathrm{Mo}(\gamma, \mathrm{n})^{99} \mathrm{Mo}$} \\
\cline { 2 - 5 } & Simul. & S-model & Simul. & S-model \\
\hline 40 & 3.24 & 3.48 & 1.92 & 1.74 \\
\hline 60 & 4.54 & 5.04 & 2.44 & 2.23 \\
\hline 80 & 5.32 & 5.83 & 2.76 & 2.48 \\
\hline 95 & 5.72 & 6.24 & 2.92 & 2.60 \\
\hline
\end{tabular}

The observed systematic overestimation of CPC obtained within the S-model for the reaction ${ }^{58} \mathrm{Ni}(\gamma, \mathrm{n}){ }^{57} \mathrm{Ni}$ ( $7 \ldots 11 \%$ depending on the electron beam energy) can be explained by the excess of cross-section represented by Lorentzian at the edges of the excitation function as compared with its description in the TALYS library (see Fig. 2,a). In its turn for the ${ }^{100} \operatorname{Mo}(\gamma, n){ }^{99}$ Mo reaction, the 
excess of $\mathrm{CPC}$ calculated by $\mathrm{MC}$ technique as against the results of S-model (from 9 to $12 \%$ ) may be elucidated by the offset of Lorentzian cross-section into the region of higher photon energy, where their flux is decreased (see Fig. 2,b). Taking into account the simplicity of the S-model, the disarrangements can be considered acceptable.

\subsection{ESTIMATION OF FWHM AND $\sigma_{\max }$ OF EXCITATION FUNCTION}

When FWHM or $\sigma_{\max }$ of the cross-section is unknown or questionable, the application of S-model enables to solve an inverse problem - to determine those parameters using an established (e.g. experimentally measured) CPC value. So the PNC activity, measured with good accuracy at a different electron beam energy $E_{\mathrm{e}, \mathrm{i}}$, allows to calculate $Y_{0}\left(E_{\mathrm{e}, \mathrm{i}}\right)$ by the expression (2). Hence with formula (7), one can compute the product $\left[S\left(E_{\mathrm{e}, \mathrm{i}}\right) \cdot \sigma_{\max , \mathrm{i}}\right]$. Thus for a possible $\Gamma$ value, one can determine $S\left(E_{\mathrm{e}, \mathrm{i}}, \Gamma\right)$ using the formula (10), and also the corresponding maximum of the cross-section $\sigma_{\text {max }, \mathrm{i}}(\Gamma)$. For the each pair of values $\Gamma$ and $\sigma_{\max , \mathrm{i}}(\Gamma)$ obtained in such a way, it is possible to determine by MC simulations the yield of a reaction with such characteristics in a PNC, $A_{P N C}^{s i m}\left(\Gamma, \sigma_{\max , i}\right)$, and to compare it with the experimental value $A_{P N C}^{\exp }$ using the expression

$$
\operatorname{dev}^{2}\left(\Gamma, \sigma_{\max , i}\right)=\left[A_{P N C}^{s i m}\left(\Gamma, \sigma_{\max , i}\right)-A_{P N C}^{\exp }\left(E_{e, i}\right)\right]^{2} .
$$

From the condition $\operatorname{Min}\left[\sum_{i} \operatorname{dev}^{2}\left(\Gamma, \sigma_{\text {max }, i}\right)\right]$, one can estimate the range of the $\Gamma$ and $\sigma_{\max }$ parameters for the reaction under study. The characteristics of the excitation functions, complied with the condition (7) and used for calculation of $A_{P N C}^{\text {sim }}$, are listed in Tables 6,7 .

Table 6

Characteristics of ${ }^{58} \mathrm{Ni}(\gamma, n)^{57} \mathrm{Ni}$ reaction

\begin{tabular}{|c|c|c|c|c|}
\hline \multirow{2}{*}{$E_{\mathrm{e}}, \mathrm{MeV}$} & \multicolumn{4}{|c|}{$\Gamma, \mathrm{MeV}$} \\
\cline { 2 - 5 } & 6 & 7 & 8 & 9 \\
\cline { 2 - 5 } & \multicolumn{4}{|c|}{$\sigma_{\max }, \mathrm{mb}$} \\
\hline 40 & 26.4 & 23.6 & 21.6 & 20.0 \\
\hline 60 & 26.5 & 23.6 & 21.4 & 19.8 \\
\hline 80 & 26.9 & 23.9 & 21.7 & 19.9 \\
\hline 95 & 27.3 & 24.2 & 21.9 & 20.1 \\
\hline
\end{tabular}

Table 7

Characteristics of $\operatorname{Mo}(\gamma, n)^{99}$ Mo reaction

\begin{tabular}{|c|c|c|c|c|}
\hline \multirow{2}{*}{$\begin{array}{c}E_{\mathrm{e}}, \\
\mathrm{MeV}\end{array}$} & \multicolumn{4}{|c|}{$\Gamma, \mathrm{MeV}$} \\
\cline { 2 - 5 } & 3.5 & 4 & 4.5 & 5 \\
\hline 40 & 179.4 & 160.6 & 146.0 & 134.4 \\
\hline 60 & 177.9 & 158.9 & 144.2 & 132.5 \\
\hline 80 & 181.6 & 162.1 & 146.9 & 134.8 \\
\hline 95 & 183.1 & 163.3 & 147.9 & 135.7 \\
\hline
\end{tabular}

\section{NUMERICAL EXPERIMENT}

In Table 8, the findings of a numerical experiment on the determination of yield of the reference reactions in $\operatorname{PNC}\left(A_{P N C}^{N E}\right)$ from natural nickel and molybdenum $0.1 \mathrm{~mm}$ thick obtained by MC simulations with the use of data on the cross-sections taken from TALYS, are given. The statistical uncertainty of the results is not higher than $1 \%$.

Reduced activity of PNC from nickel

Table 8

Reduced activity of PNC from nickel
and molybdenum (simulations)
\begin{tabular}{|c|c|c|}
\hline \multirow{2}{*}{$\mathrm{E}_{\mathrm{e}}, \mathrm{MeV}$} & \multicolumn{2}{|c|}{$A_{P N C}^{N E} \cdot 10^{-5} \mathrm{~Bq} / \mu \mathrm{A} \cdot \mathrm{h}$} \\
\cline { 2 - 3 } & ${ }^{57} \mathrm{Ni}$ & ${ }^{99} \mathrm{Mo}$ \\
\hline 40 & 3.35 & 1.28 \\
\hline 60 & 4.80 & 1.63 \\
\hline 80 & 5.62 & 1.84 \\
\hline 95 & 6.07 & 1.95 \\
\hline
\end{tabular}

On the basis of those data, the product $\left[S\left(E_{\mathrm{e}, \mathrm{i}}\right) \cdot \sigma_{\mathrm{max}, \mathrm{i}}\right]$ was computed by the formulae (2), (7). For a number of $\Gamma$, the corresponding values of $\sigma_{\max , \mathrm{i}}$. were obtained with the use of S-factor given in Tables 3,4. For the each pair $\left(\Gamma, \sigma_{\mathrm{max}, \mathrm{i}}\right)$, the corresponding activity $A_{P N C}^{\text {sim }}$ was calculated by $\mathrm{MC}$ technique, and also the deviation $\operatorname{dev}^{2}\left(\Gamma, \sigma_{\max , i}\right)$ was determined by (11). From the condition of minimal $\sum_{i} d e v^{2}$, the range of the possible $\Gamma$ and $\sigma_{\max }$ values was found (Fig. 3).
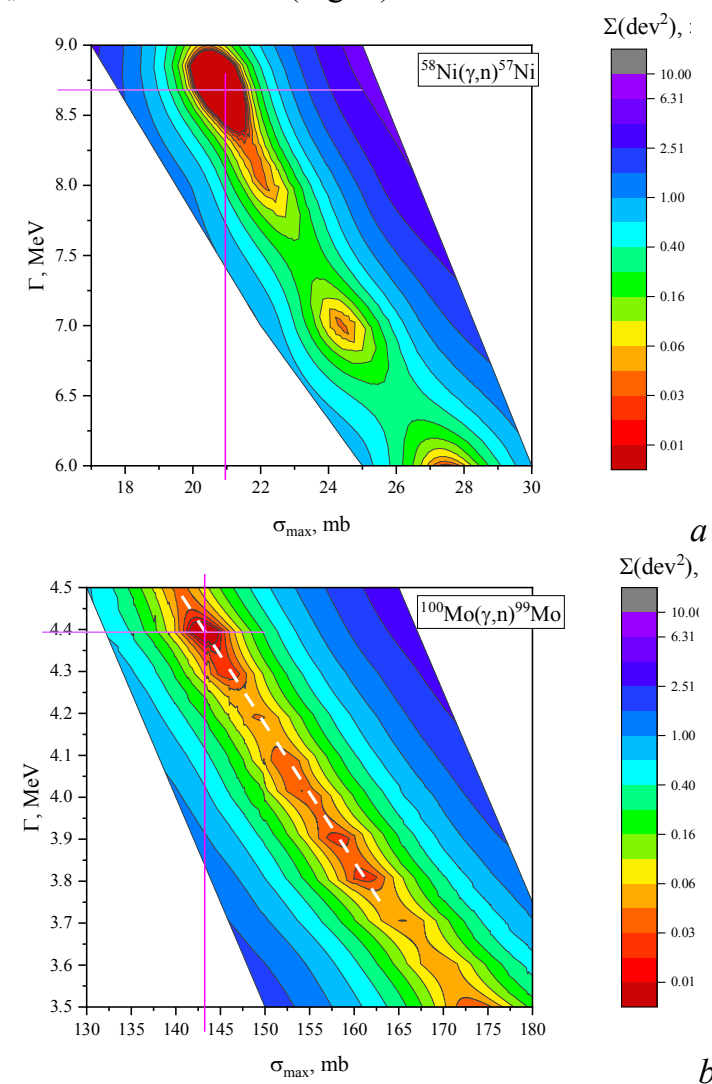

Fig. 3. Distribution of deviations square sums of yield simulation results from reference data ${ }^{58} \mathrm{Ni}(\gamma, n){ }^{57} \mathrm{Ni}^{100}(\mathrm{a}) ; \mathrm{Mo}(\gamma, n){ }^{99} \mathrm{Mo}(b)$ 
It is seen, that for the ${ }^{58} \mathrm{Ni}(\gamma, \mathrm{n})^{57} \mathrm{Ni}$ reaction the region of most probable $\left(\Gamma, \sigma_{\max }\right)$ lies within $(8 \ldots 9 \mathrm{MeV}$; $20 \ldots 22 \mathrm{mb}$ ) with minimal sum of deviations near the pair $(8.7 \mathrm{MeV} ; 21 \mathrm{mb})$. For the reaction ${ }^{100} \mathrm{Mo}(\gamma, \mathrm{n}){ }^{99} \mathrm{Mo}$, that range is $(3.7 \ldots 4.5 \mathrm{MeV} ; 142 \ldots 163 \mathrm{mb})$ with minimal deviation close to (4.39 MeV; $143.2 \mathrm{mb})$.

\section{CONCLUSIONS}

For a reaction with dominating GDR, the developed analytical model of isotope production in a high-energy X-ray flux has established the connection between the $\Gamma$ and $\sigma_{\max }$ parameters of the excitation function, represented in the Lorentzian form, via the normalized activity of a target in the shape of a PNC. That characteristics can be experimentally measured with high precision. For each pair of the $\left(\Gamma, \sigma_{\max }\right)$ parameters, which formally meets that connection, one can obtain by $\mathrm{MC}$ simulations the corresponding yield of the reaction in PNC at a given end-point energy of X-rays, compare it with the experimental yield and determine in such a way the actual range of the $\Gamma$ and $\sigma_{\max }$ values.

The factors affecting the uncertainty of the determination of GDR gross-structure parameters by the proposed technique are:

- the accuracy of the determination of PNC activity;

-the accuracy of the analytical model determined in turn by;

- the accuracy of the analytical description of X-ray radiation spectrum;

- the accuracy of the approximation of excitation function by Lorentzian.

The results of the experimental checking of novel method are presented in the second part of the work.

\section{REFERENCES}

1. Handbook on photonuclear data for applications. Cross-sections and spectra, IAEA-TECDOC-1178, IAEA, Vienna, Austria, 2000.

2. V.V. Varlamov, B.S. Ishkanov. Modern status of photonuclear data // Phys. of Atom. Nucl. 2017, v. 80 , p. $957-967$.

3. TALYS-1.95, https://tendl.web.psi.ch/tendl 2019/talys.html

4. S.C. Fultz, B.A. Alvarez, B.L. Berman, P. Meyer. Photoneutron cross sections of ${ }^{58} \mathrm{Ni}$ and ${ }^{60} \mathrm{Ni} / /$ Physical Review C. 1974, v. 10, № 2, p. 608-619.

5. H. Beil, R. Bergere, P. Carlos, A. Lepretre, A. DeMiniac, A. Veyssiere. A study of the photoneutron contribution to the giant dipole resonance in doubly even Mo isotopes // Nuclear Physics Section A. 1974, v. 227, p. 427.

6. V.L. Uvarov. On critical parameters of photonuclear isotope production // Problems of Atomic Science and Technology. Series "Nuclear Physics Investigations”. 2019, № 6, p. 153-157.

7. S.P. Karasyov, V.I. Nikiforov, R.I. Pomatsalyuk, V.A. Shevchenko, I.N. Shlyakhov, A.Eh. Tenishev, V.L. Uvarov, Yu.V. Zhebrovsky. High-Intensity Bremsstrahlung Monitoring System for Photonuclear Technologies // Proc. Of EPAC 2006 (Edinburgh, Scotland, 2006), p. 1235-1237.

8. V.I. Nikiforov, V.L. Uvarov. A method for estimation of isotope yield in a thick target under photonuclear production // NIM B 269. 2011, p. 3149-3152.

9. M.I. Aizatskyi, V.I. Beloglasov, V.N. Boriskin, et al. State and Prospects of the Linac of Nuclear-Physics Complex with Energy of Electrons up to $100 \mathrm{MeV} / /$ Problems of Atomic Science and Technology. Series “Nuclear Physics Investigations". 2014, № 3, p. 60-63.

10. J. Allison, K. Amako, J. Apostolakis, et al. Recent developments in Geant4 // NIM. 2016, A835, p. 186-225.

Article received 16.04.2021

\section{ОЦЕНКА ПАРАМЕТРОВ ГРОСС-СТРУКТУРЫ ГИГАНТСКОГО ДИПОЛЬНОГО РЕЗОНАНСА: 1. МЕТОД}

\section{В.Л. Уваров, А.А. Захарченко}

Имеющиеся данные по фотоядерным сечениям, как полученные экспериментально, так и на основе теоретических моделей, иногда характеризуются значительным разбросом. Описан простой метод оценки ширины $(\mathrm{FWHM})$ и максимума $\left(\sigma_{\max }\right)$ функции возбуждения реакции с доминированием гигантского дипольного резонанса. Разработана аналитическая модель для описания генерации изотопов в пучке тормозного излучения. Показано, что по известному выходу реакции в тонкой мишени, полностью перекрывающей пучок с заданной граничной энергией фотонов, можно установить область значений $\sigma_{\max }$ и FWHM. Возможности нового подхода продемонстрированы на референтных реакциях с использованием метода численного эксперимента.

\section{ОЦІНКА ПАРАМЕТРІВ ГРОСС-СТРУКТУРИ ГІГАНТСЬКОГО ДИПОЛЬНОГО РЕЗОНАНСУ: 1. МЕТОД}

\section{В.Л. Уваров, О.О. Захарченко}

Наявні дані з фотоядерних перетинів, як такі, що одержані експериментально, так і на основі теоретичних моделей, інколи характеризуються значним розкидом. Описано простий метод оцінки ширини (FWHM) i максимуму $\left(\sigma_{\max }\right)$ функції збудження реакції з домінуванням гігантського дипольного резонансу. Розроблена аналітична модель для опису генерації ізотопів в пучку гальмівного випромінення. Показано, що за відомим виходом реакції у тонкій мішені, яка повністю перекриває пучок з наданою граничною енергією фотонів, можна встановити область значень $\sigma_{\max }$ та FWHM. Можливості нового підходу продемонстровані на референтних реакціях з використанням методу чисельного експерименту. 